\title{
Synthesis of Photoreactive Imidazole Derivatives and Thermal Curing Reaction of Epoxy Resins Catalyzed by Photo-Generated Imidazole
}

\author{
Tadatomi Nishikubo, ${ }^{\dagger}$ Atsushi KameYama, and Yoshiyasu Toya \\ Department of Applied Chemistry, Faculty of Engineering, Kanagawa University, \\ Rokkakubashi, Kanagawa-ku, Yokohama, 221 Japan
}

(Received November 6, 1996)

\begin{abstract}
Photoreactive blocked imidazoles such as $N$-(2-nitrobenzyloxycarbonyl)imidazole (2-NBCI), $N$-(3-nitrobenzyloxycarbonyl)imidazole (3-NBCI), $N$-(4-nitrobenzyloxycarbonyl)imidazole (4-NBCI), $N$-(4-chloro-2-nitrobenzyloxycarbonyl)imidazole (CNBCI), $N$-(5-methyl-2-nitrobenzyloxycarbonyl)imidazole (MNBCI), and $N$-(4,5-dimethoxy-2-nitrobenzyloxycarbonyl)imidazole (DNBCI) were synthesized in good yields by reactions of $N, N^{\prime}$-carbonyldiimidazole (CDI) with corresponding benzyl alcohols. The prepared 2-NBCI decomposed smoothly to produce imidazole by UV-irradiation in tetrahydrofuran (THF) solution or poly(methyl methacrylate) (PMMA) film. Rates of photolysis of DNBCI, MNBCI and CNBCI were higher than that of 2-NBCI in PMMA film, although the rates of 3-NBCI and 4-NBCI were slower than that of 2-NBCI in PMMA film under the same conditions. Thermal curing reactions of epoxy resins and poly(glycidyl methacrylate-co-methyl methacrylate) $\left[\mathrm{P}\left(\mathrm{GMA}_{55}-\mathrm{MMA}_{45}\right)\right]$ using photo-generated imidazole were examined at $100-160^{\circ} \mathrm{C}$. The ring opening reaction of epoxide groups, confirmed by IR spectra, in epoxy resins and $\mathrm{P}\left(\mathrm{GMA}_{55}-\mathrm{MMA}_{45}\right)$ proceeded smoothly by catalysis of the photo-generated imidazole.
\end{abstract}

KEY WORDS Synthesis of Blocked Imidazole / Photo-Generation / Imidazole / Thermal Curing Reaction

/ Epoxy Resin / Poly(glycidyl methacrylate-co-methyl methacrylate) /

Epoxy resins are typical thermo-setting resins, and widely used for coatings, paints, adhesives, composite, for sealing, packaging, and so on in industry. Thermal curing reactions of epoxy resins are normally performed with hardeners ${ }^{1,2}$ such as polyfunctional amines, carboxylic acids, carboxylic acid anhydrides, phenols, thiols, and active esters. Thermal crosslinking reactions of epoxy resins were also carried out with appropriate acidic catalysts or basic catalysts such as imidazole compounds. However, storage stability of the mixtures of epoxy resins with hardeners or catalysts has not been satisfactory at room temperature. To solve the above problem in the epoxy resin mixtures, many technical methods have been investigated to increase the storage stability of epoxy resins containing hardeners or catalysts. Pappas and his co-workers propose ${ }^{3}$ some benzylsulfonium salts as acidic thermal latent catalysts, which decompose to produce the corresponding benzyl cations ${ }^{4}$ by heating and enhanced the thermal crosslinking reaction of epoxy resins at elevated temperatures. Endo et al. reported that benzylpyridinium salts, ${ }^{5}$ benzylphosphonium salts, ${ }^{6}$ and hydrazinium salts ${ }^{7}$ can be used as thermal latent catalysts for the polymerization of epoxy compounds as did as benzylsulfonium salts. Crivello et $a l^{8,9}$ reported that certain triarylsulfonium salts and diaryliodonium salts containing $\mathrm{BF}_{4}, \mathrm{PF}_{6}, \mathrm{AsF}_{6}$, and $\mathrm{SbF}_{6}$ as counter anions are used as photo-initiating cationic catalyst for the crosslinking reactions of polyfunctional epoxy compounds, because these triarylsulfonium salts and diaryliodonium salts decompose to produce corresponding $\mathrm{Br} \phi$ nsted acids upon UVirradiation.

Winkle et al. reported ${ }^{10}$ the photo-generation of free amines from 2-nitrobenzyl carbamates upon irradiation with UV-light. Kutal et al. examined ${ }^{11}$ photo-generation of ammonia by the reaction of a cobalt-amine complex.

\footnotetext{
$\dagger$ To whom all correspondence should be addressed.
}

Tsunooka et al. ${ }^{12}$ reported the photo-generation of free amines from the reactions of $O$-acyloxyamines. Cameron et $a l .{ }^{13}$ reported the photo-generation of polyfunctional free amines such as hexamethylenediamine (HMDA) by the photochemical reaction of certain blocked polyfunctional amines.

The authors recently reported ${ }^{14}$ the photo-generation of various polyfunctional free amines from certain blocked polyfunctional amine compounds followed by novel thermal curing reactions of epoxy resins and polyurethane oligomers. The authors also reported ${ }^{15}$ the photo-generation of polyfunctional free thiols from blocked polyfunctional thiol compounds and thermal crosslinking reactions of epoxy resins with photogenerated polyfunctional thiols. However, equimolar amounts of the reagents were needed ordinarily when the thermal crosslinking reactions of epoxy resins with photo-generated hardeners were carried out. Therefore, the photo-generation of base catalyst from the blocked compounds upon UV-irradiation and application to the curative formulation of epoxy resins represent key advances in photopolymer chemistry. This paper reports the synthesis of blocked imidazole compounds, photogeneration of free imidazole, and thermal curing reaction of epoxy resins catalyzed by the produced imidazole.

\section{EXPERIMENTAL}

\section{Materials}

Organic solvents were dried using $\mathrm{P}_{2} \mathrm{O}_{5}, \mathrm{CaH}_{2}$, or Na metal wire and purified by the usual method before use. Commercial epoxy resins such as Epicoat 828 (epoxide equivalent: 190) and DEN 438 (epoxide equivalent: 181) were used without further purification. Reagent grade $N, N^{\prime}$-carbonyldiimidazole (CDI), 2-nitrobenzyl alcohol, 3-nitrobenzyl alcohol, 4-nitrobenzyl alcohol, 4-chloro-2nitrobenzyl alcohol, 5-methyl-2-nitrobenzyl alcohol, and 4,5-dimethoxy-2-nitrobenzyl alcohol were used without 
further purification. Poly(methyl methacrylate) (PMMA) $\left(M_{n}=64300, M_{w} / M_{n}=1.29\right)$ was donated from Professor Nakamura's Laboratory, Kanagawa University, and was used without further purification. Poly(glycidyl methacrylate-co-methyl methacrylate) containing a pendant epoxide group (epoxide equivalent: 223$)\left[\mathrm{P}\left(\mathrm{GMA}_{55}\right.\right.$ $\left.\left.\mathrm{MMA}_{45}\right)\right]\left(M_{n}=43700, M_{w} / M_{n}=1.56\right)$ was synthesized by the radical copolymerization of glycidyl methacrylate $(50 \mathrm{~mol} \%)$ and methyl methacrylate $(50 \mathrm{~mol} \%)$ using azobisisoburyronitrile (AIBN) as an initiator in dimethylformamide (DMF) at $60^{\circ} \mathrm{C}$ for $12 \mathrm{~h}$ according to the reported method. ${ }^{16}$

\section{Measurement}

Infrared (IR) spectra were measured on a JASCO model IR-700 spectrometer. ${ }^{1} \mathrm{H}$ NMR spectra were recorded on a JEOL model JNM FX-200 $(200 \mathrm{MHz})$ using deuterated solvents and $\mathrm{Me}_{4} \mathrm{Si}$ (tetramethylsilane, TMS) as the internal standard. UV spectra were obtained on a Shimadzu model UV-2100S UV-VIS spectrophotometer. Molecular weights of the polymers were estimated by gel permeation chromatography (GPC) with the use of a model LC-909 GPC (Japan Analytical Industry Co., Ltd.) equipped with a refractive index detector using JAIGEL-1HA-F and JAIGEL-1H-A gel columns (eluent: tetrahydrofuran (THF), calibrated with narrow molecular weight polystyrene standards). Thermal analysis was performed on a Seiko Electronic model TG/GTA 200 at a heating rate $10^{\circ} \mathrm{C} \mathrm{min}^{-1}$ for thermogravimetric analysis (TGA) under nitrogen atmosphere.

\section{Synthesis of N-(2-Nitrobenzyloxycarbonyl)imidazole (2- $N B C I)$}

$\mathrm{N}$-(2-Nitrobenzyloxycarbonyl)imidazole (2-NBCI) (mp $\left.143-144^{\circ} \mathrm{C}\right)[\mathrm{UV}$ (in THF): $241 \mathrm{~nm}(\varepsilon=8500)]$ was synthesized in $74 \%$ yield by the reaction of 2-nitrobenzyl alcohol with of CDI in acetonitrile according to the reported method. ${ }^{15}$

\section{Synthesis of $\mathrm{N}$-(3-Nitrobenzyloxycarbonyl)imidazole (3- $N B C I)$}

CDI $(0.973 \mathrm{~g} ; 6 \mathrm{mmol})$ was dissolved in acetonitrile $(15 \mathrm{~mL})$, and a solution of 3-nitrobenzyl alcohol $(0.766 \mathrm{~g}$; $5 \mathrm{mmol})$ in acetonitrile $(5 \mathrm{~mL})$ was added to this solution at room temperature for $1 \mathrm{~h}$ under stirring. The solution was stirred at room temperature for $4 \mathrm{~h}$, and the solvent was evaporated in vacuo. The crude product was dissolved in chloroform, washed with water, dried with anhydrous magnesium sulfate for overnight, and the chloroform was evaporated. The product thus obtained was recrystallized from ethyl acetate. The yield of 3-NBCI was $0.964 \mathrm{~g}$ $(78 \%)$ mp $106-107^{\circ} \mathrm{C}$. IR $(\mathrm{KBr}): 1770(\mathrm{C}=\mathrm{O}), 1528$ and $1346\left(-\mathrm{NO}_{2}\right)$, and $1181 \mathrm{~cm}^{-1}(\mathrm{C}-\mathrm{O}-\mathrm{C})$. UV (in THF): $252 \mathrm{~nm}(\varepsilon=7430) .{ }^{1} \mathrm{H}$ NMR $\left(200 \mathrm{MHz}, \mathrm{CDCl}_{3}\right.$, TMS): $\delta=5.5\left(\mathrm{~s}, 2 \mathrm{H}, \mathrm{CH}_{2}\right), 7.1(\mathrm{~s}, 1 \mathrm{H}, \mathrm{C}=\mathrm{CH}), 7.4-7.5$, $(\mathrm{m}, 1 \mathrm{H}, \mathrm{CH}=\mathrm{C})$, and $7.6-8.4 \mathrm{ppm}(\mathrm{m}, 5 \mathrm{H}, \mathrm{N}=\mathrm{CH}$ and aromatic protons).

Anal. Calcd for $\mathrm{C}_{11} \mathrm{H}_{9} \mathrm{~N}_{3} \mathrm{O}_{4}: \mathrm{C}, 53.44 \% ; \mathrm{H}, 3.67 \%$; N, $17.00 \%$. Found: C, $53.64 \% ; \mathrm{H}, 3.97 \%$; N, 16.70\%.

\section{Synthesis of $\mathrm{N}$-(4-Nitrobenzyloxycarbonyl)imidazole (4-} $N B C I$ )

The reaction of CDI $(0.811 \mathrm{~g} ; 5 \mathrm{mmol})$ with 4-nitro- benzyl alcohol $(0.766 \mathrm{~g} ; 5 \mathrm{mmol})$ was carried out in acetonitrile $(20 \mathrm{~mL})$ at room temperature for $24 \mathrm{~h}$, and the crude product obtained by the same method was recrystallized from ethyl acetate. The yield of 4-NBCI was $0.911 \mathrm{~g}(74 \%)$. mp $128-129^{\circ} \mathrm{C}$. IR $(\mathrm{KBr}): 1756$ $(\mathrm{C}=\mathrm{O}), \quad 1512$ and $1350 \quad\left(-\mathrm{NO}_{2}\right)$, and $1181 \mathrm{~cm}^{-1}$ (C-O-C). UV (in THF): $263 \mathrm{~nm}(\varepsilon=13650) .{ }^{1} \mathrm{H}$ NMR $\left(200 \mathrm{MHz}, \mathrm{CDCl}_{3}, \mathrm{TMS}\right): \delta=5.5\left(\mathrm{~s}, 2 \mathrm{H}, \mathrm{CH}_{2}\right), 7.1(\mathrm{~s}$, $1 \mathrm{H}, \mathrm{CH}=\mathrm{C}), 7.4-7.5,(\mathrm{~m}, 1 \mathrm{H}, \mathrm{CH}=\mathrm{C})$, and $7.6-8.3$ ppm (m, $5 \mathrm{H}, \mathrm{N}=\mathrm{CH}$ and aromatic proton).

Anal. Calcd for $\mathrm{C}_{11} \mathrm{H}_{9} \mathrm{~N}_{3} \mathrm{O}_{4}$ : C, 53.44\%; H, 3.67\%; N, $17.00 \%$. Found: C, $53.16 \%$; H, 3.64\%; N, $17.23 \%$.

\section{Synthesis of N-(4-Chloro-2-nitrobenzyloxycarbonyl)imid-} azole $(C N B C I)$

CNBCI was synthesized by reaction of CDI $(0.811 \mathrm{~g}$; $5 \mathrm{mmol}$ ) with 4-chloro-2-nitrobenzyl alcohol $(0.938 \mathrm{~g}$; $5 \mathrm{mmol})$ in acetonitrile $(15 \mathrm{~mL})$ at room temperature for $24 \mathrm{~h}$ under stirring, and the crude product was recrystallized from ethyl acetate. The yield of CNBCI was $1.12 \mathrm{~g}(79 \%)$. mp $140-141^{\circ} \mathrm{C}$. IR $(\mathrm{KBr}): 1762$ $(\mathrm{C}=\mathrm{O}), 1525$ and $1362\left(-\mathrm{NO}_{2}\right)$, and $1181 \mathrm{~cm}^{-1}(\mathrm{C}-\mathrm{O}-\mathrm{C})$. UV (in THF): $243(\varepsilon=7900)$ and $303(\varepsilon=1800) \mathrm{nm} .{ }^{1} \mathrm{H}$ NMR (200 MHz, $\left.\mathrm{CDCl}_{3}, \mathrm{TMS}\right): \delta=5.8\left(\mathrm{~s}, 2 \mathrm{H}, \mathrm{CH}_{2}\right)$, $7.1(\mathrm{~s}, 1 \mathrm{H}, \mathrm{CH}=\mathrm{C}), 7.4-7.5,(\mathrm{~m}, 1 \mathrm{H}, \mathrm{CH}=\mathrm{C})$, and 7.6-8.3 ppm (m, $4 \mathrm{H}, \mathrm{N}=\mathrm{CH}$ and aromatic proton).

Anal. Calcd for $\mathrm{C}_{11} \mathrm{H}_{8} \mathrm{~N}_{3} \mathrm{O}_{4} \mathrm{Cl}$ : C, $46.91 \% ; \mathrm{H}, 2.86 \%$; N, $14.92 \%$. Found: C, $47.08 \%$; H, $2.81 \%$; N, 14.90\%.

\section{Synthesis of N-(5-Methyl-2-nitrobenzyloxycarbonyl)imid- azole $(M N B C I)$}

The reaction of $0.973 \mathrm{~g}(6 \mathrm{mmol})$ of CDI with $0.836 \mathrm{~g}$ $(5 \mathrm{mmol})$ of 5-methyl-2-nitrobenzyl alcohol was performed in THF $(25 \mathrm{~mL})$ at room temperature for $24 \mathrm{~h}$ under nitrogen, and THF was evaporated in vacuo. The mixture was diluted with chloroform, washed several times with water, and dried with anhydrous magnesium sulfate for overnight. Chloroform was evaporated from the solution and the product was recrystallized from methanol. The yield of MNBCI was $1.18 \mathrm{~g} \mathrm{(94 \% ).} \mathrm{mp}$ $81-82^{\circ} \mathrm{C}$. IR $(\mathrm{KBr}): 1762(\mathrm{C}=\mathrm{O}), 1514$ and 1336 $\left(-\mathrm{NO}_{2}\right)$, and $1175 \mathrm{~cm}^{-1}(\mathrm{C}-\mathrm{O}-\mathrm{C})$. UV (in THF): $274 \mathrm{~nm}$ $(\varepsilon=3100) .{ }^{1} \mathrm{H}$ NMR $\left(200 \mathrm{MHz}, \mathrm{CDCl}_{3}, \mathrm{TMS}\right): \delta=2.5$ $\left(\mathrm{s}, 3 \mathrm{H}, \mathrm{CH}_{3}\right), 5.8\left(\mathrm{~s}, 2 \mathrm{H}, \mathrm{CH}_{2}\right), 7.1(\mathrm{~s}, 1 \mathrm{H}, \mathrm{CH}=\mathrm{C})$, 7.3-7.6, (m, $3 \mathrm{H}, \mathrm{CH}=\mathrm{C}$ and aromatic protons), and $8.1-8.2 \mathrm{ppm}(\mathrm{m}, 2 \mathrm{H}, \mathrm{N}=\mathrm{CH}$ and aromatic proton).

Anal. Calcd for $\mathrm{C}_{12} \mathrm{H}_{11} \mathrm{~N}_{3} \mathrm{O}_{4}$ : C, $55.17 \% ; \mathrm{H}, 4.24 \%$. Found: C, $55.27 \%$; H, $4.29 \%$.

\section{Synthesis of N-(4,5-Dimethoxy-2-nitrobenzyloxycarbonyl)- imidazole $(D N B C I)$}

CDI $(0.973 \mathrm{~g} ; 6 \mathrm{mmol})$ was made to react with $4,5-$ dimethoxy-2-nitrobenzyl alcohol $(0.639 \mathrm{~g} ; 3 \mathrm{mmol})$ in THF $(40 \mathrm{~mL})$ at $0^{\circ} \mathrm{C}$ for $6 \mathrm{~h}$, and the solvent was evaporated in vacuo. The obtained crude product by the same method was recrystallized twice from ethyl acetate. The yield of DNBCI was $0.664 \mathrm{~g}(72 \%) . \mathrm{mp} 135-137^{\circ} \mathrm{C}$. IR $(\mathrm{KBr}): 1766(\mathrm{C}=\mathrm{O}), 1525$ and $1332\left(-\mathrm{NO}_{2}\right)$, and $1178 \mathrm{~cm}^{-1}$ (C-O-C). UV (in THF): $342 \mathrm{~nm}(\varepsilon=2460)$. ${ }^{1} \mathrm{H}$ NMR $\left(200 \mathrm{MHz}, \mathrm{CDCl}_{3}, \mathrm{TMS}\right): \delta=4.0(\mathrm{~s}, 6 \mathrm{H}$, $\left.\mathrm{O}-\mathrm{CH}_{3}\right), 5.8\left(\mathrm{~s}, 2 \mathrm{H}, \mathrm{CH}_{2}\right), 7.0(\mathrm{~s}, 1 \mathrm{H}$, aromatic proton), $7.1(\mathrm{~s}, 1 \mathrm{H}, \mathrm{CH}=\mathrm{C}), 7.5,(\mathrm{~s}, \mathrm{H}, \mathrm{CH}=\mathrm{C}), 7.8(\mathrm{~s}, 1 \mathrm{H}$, aromatic proton), and $8.2 \mathrm{ppm}(\mathrm{m}, 1 \mathrm{H}, \mathrm{N}=\mathrm{CH})$. 
Anal. Calcd for $\mathrm{C}_{13} \mathrm{H}_{13} \mathrm{~N}_{3} \mathrm{O}_{6}$ : C, $50.82 \% ; \mathrm{H}, 4.26 \%$. Found: C, $51.09 \% ; \mathrm{H}, 4.20 \%$.

\section{Typical Procedure for Photolysis of Blocked Imidazole in Solution}

An 2-NBCI solution $(0.371 \mathrm{~g} ; 1.5 \mathrm{mmol})$ in THF $\left(0.05 \mathrm{~mol} \mathrm{~L}^{-1} ; 30 \mathrm{~mL}\right)$ was charged into a small cylindrical quartz reactor with a water jacket and a thermometer. Gaseous nitrogen was bubbled through the solution for $30 \mathrm{~min}$ before UV irradiation. Photolysis of the 2-NBCI was carried out using a 500-W high-pressure mercury lamp (Ushio Electric Co., USH-500D) with thermal-ray filter (HA-50) under nitrogen atmosphere at $30^{\circ} \mathrm{C}$ for $6 \mathrm{~h}$. During photo-irradiation, the intensity of incident light was kept always at $1.92-1.98 \mathrm{~mW} \mathrm{~cm}^{-2}$ (at $310 \mathrm{~nm}$ ). THF was evaporated in vacuo. The ${ }^{1} \mathrm{H}$ NMR spectrum (in $\mathrm{CDCl}_{3}$ ) of the reaction mixture showed decrease of methylene protons of $2-\mathrm{NBCI}$ at $\delta=5.8 \mathrm{ppm}$, and conversion was calculated from the intensity of methylene protons at $\delta=5.8 \mathrm{ppm}$ and methine proton at $\delta=7.1 \mathrm{ppm}$ due to the imidazole ring.

\section{Typical Procedure for Photolysis of Blocked Imidazole in PMMA Film}

PMMA $(0.3 \mathrm{~g})$ and 2-NBCI $(0.025 \mathrm{~g} ; 1 \mathrm{mmol})$ were dissolved in THF $(5 \mathrm{~mL})$. The solution was cast on a $\mathrm{KBr}$ plate and dried to make a polymer film. The film was irradiated by a $250-\mathrm{W}$ high-pressure mercury lamp (Ushio Electric Co., USH-250D) without a filter. The intensity of the light was kept at $10.0 \mathrm{~mW} \mathrm{~cm}^{-2}$ (at $310 \mathrm{~nm}$ ). Decreasing rate of the $\mathrm{NO}_{2}$ group of 2-NBCI at $1523 \mathrm{~cm}^{-1}$ was measured by IR spectroscopy.

\section{Typical Procedure for Photolysis of Blocked Imidazole in} Epoxy Resin and Thermal Curing Reaction of Epoxy Resin with Photo-Generated Imidazole

The rate of the thermal curing reaction of epoxy resin was measured as follows. Epicoat $828(0.380 \mathrm{~g} ; 2 \mathrm{mmol}$ as epoxy group) and 2-NBCI $(0.049 \mathrm{~g} ; 0.2 \mathrm{mmol})$ were mixed in an agate mortar and the paste mixture was cast on a $\mathrm{KBr}$ plate. The mixture on the plate was irradiated by a $250-\mathrm{W}$ high-pressure mercury lamp (Ushio Electric Co., USH-250D) without a filter under nitrogen atmosphere. The intensity of the light was kept at 10.8 $\mathrm{mW} \mathrm{cm} \mathrm{cm}^{-2}$ (at $310 \mathrm{~nm}$ ). The rate of decrease of the cyclic $\mathrm{C}-\mathrm{O}-\mathrm{C}$ group of the epoxy resin at $910 \mathrm{~cm}^{-1}$ in the mixture with photo-generated imidazole by heating at $120^{\circ} \mathrm{C}$ was measured by IR spectroscopy.
Typical Procedure for Thermal Curing Reaction of $P\left(G M A_{55}-M M A_{45}\right)$ using Photo-Generated Imidazole $\mathrm{P}\left(\mathrm{GMA}_{55}-\mathrm{MMA}_{45}\right)(0.555 \mathrm{~g} ; 2.5 \mathrm{mmol}$ as epoxide group) and 2-NBCI $(0.031 \mathrm{~g} ; 0.125 \mathrm{mmol})$ were dissolved in THF $(5 \mathrm{~mL})$. The solution was cast on a $\mathrm{KBr}$ plate and dried to make a polymer film on the plate. The film was irradiated under the same conditions as for the reaction of epoxy resin with $2-\mathrm{NBCI}$, and the polymer film irradiated for $10 \mathrm{~min}$ was heated at $120^{\circ} \mathrm{C}$. Decreasing rate of the cyclic $\mathrm{C}-\mathrm{O}-\mathrm{C}$ group at $910 \mathrm{~cm}^{-1}$ was recorded by the IR spectroscopy.

\section{RESULTS AND DISCUSSION}

\section{Synthesis of Blocked Imidazol}

Photoreactive various blocked imidazole derivatives were synthesized by reactions of CDI with certain nitrobenzyl alcohols in acetonitrile or THF. The reaction conditions and results are summarized in Table I. Reactions of CDI with 3-nitrobenzyl alcohol, 4nitrobenzyl alcohol and 4-chloro-2-nitrobenzyl alcohol proceeded very smoothly in acetonitrile at room temperature, and the corresponding blocked imidazoles such as 3-NBCI, 4-NBCI, and CNBCI were obtained in 78,74 , and $79 \%$ yields, respectively (Scheme 1 ). When the reaction of CDI with 5-methyl-2-nitrobenzyl alcohol was performed under the same conditions, the production of small amounts of MNBCI and large amounts of by-products was confirmed by thin layer chromatography. MNBCI was synthesized in high yield (94\%) when the reaction was carried out with 1.2 times CDI in THF at room temperature. DNBCI was yielded in $72 \%$ by the reaction of 2.0 times CDI with 4,5-dimethoxy-2-nitrobenzyl alcohol in THF at $0^{\circ} \mathrm{C}$, although a by-product, $\operatorname{di}(4,5$-dimethoxy-2-nitrobenzyl)carbonate, was obtained by equimolar reaction at room temperature. These results indicate that blocked imidazole compounds such as 2-NBCI, 3-NBCI, 4-NBCI, and CNBCI are readily obtained by reactions of $\mathrm{CDI}$ and nitrobenzyl

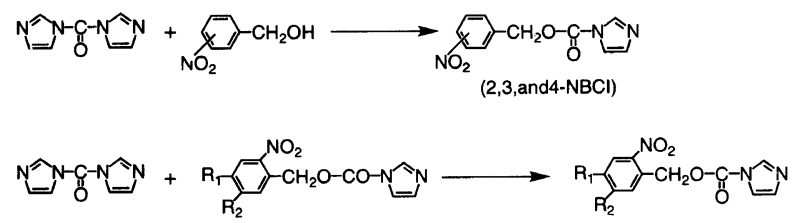

$R_{1}=C l, R_{2}=H(C N B C l) ; R_{1}=H, R_{2}=\mathrm{CH}_{3}(M N B C l)$,
$R_{1}=R_{2}=\mathrm{OCH}_{3}(\mathrm{DNBCl})$

Scheme 1.

Table I. Synthesis and properties of blocked imidazole derivatives

\begin{tabular}{|c|c|c|c|c|c|c|c|c|c|}
\hline \multirow{2}{*}{$\begin{array}{c}\text { Run } \\
\text { no }\end{array}$} & \multirow{2}{*}{$\begin{array}{l}\text { Blocked } \\
\text { imidazole }\end{array}$} & \multirow{2}{*}{$\begin{array}{l}\text { Reaction } \\
\text { solvent }\end{array}$} & \multirow{2}{*}{$\frac{\text { Temp. }}{{ }^{\circ} \mathrm{C}}$} & \multirow{2}{*}{$\frac{\text { Time }}{h}$} & \multirow{2}{*}{$\frac{\text { Yield }}{\%}$} & \multirow{2}{*}{$\frac{\mathrm{Mp}}{{ }^{\circ} \mathrm{C}}$} & \multirow{2}{*}{$\frac{T_{\mathrm{d}}^{\mathrm{a}}}{{ }^{\circ} \mathrm{C}}$} & \multirow{2}{*}{\multicolumn{2}{|c|}{$\frac{\lambda_{\max }^{\mathrm{b}}}{\mathrm{nm}}$}} \\
\hline & & & & & & & & & \\
\hline 2 & 3-NBCI & Acetonitrile & Room temp. & 5 & 78 & 106 & 149 & 252 & $(7430)^{\mathrm{c}}$ \\
\hline 3 & 4-NBCI & Acetonitrile & Room temp. & 24 & 74 & 128 & 157 & 263 & $(13650)^{\mathrm{c}}$ \\
\hline 4 & CNBCI & Acetonitrile & Room temp. & 24 & 79 & 140 & 172 & 243 & $(7900)^{c}$ \\
\hline 5 & MNBCI & THF & Room temp. & 24 & 94 & 81 & 154 & 274 & $(3100)^{\mathrm{c}}$ \\
\hline 6 & DNBCI & THF & 0 & 6 & 72 & 135 & 158 & 342 & $(2460)^{\mathrm{c}}$ \\
\hline
\end{tabular}

${ }^{\mathrm{a}} T_{\mathrm{d}}$, temperature of initial weight loss. ${ }^{\mathrm{b}}$ Measured in THF. ${ }^{\mathrm{c}} \varepsilon$, the absorption maximum. 
Table II. Solubility of blocked imidazole derivatives ${ }^{\mathbf{a}}$

\begin{tabular}{|c|c|c|c|c|c|c|}
\hline Solvent & 2-NBCI & 3-NBCI & 4-NBCI & CNBCI & MNBCI & DNBCI \\
\hline$n$-Hexane & - & - & - & - & + & - \\
\hline Diethyl ether & - & - & + & - & + & - \\
\hline Ethyl acetate & + & + & + & + & ++ & + \\
\hline Acetone & ++ & ++ & ++ & ++ & ++ & ++ \\
\hline Acetonitrile & + & ++ & ++ & + & ++ & + \\
\hline Chloroform & ++ & ++ & ++ & ++ & ++ & ++ \\
\hline THF & ++ & ++ & ++ & ++ & ++ & + \\
\hline
\end{tabular}

${ }^{a}++$, soluble at room temperature; + , soluble by heating; - , insoluble.

alcohols with low nucleophilicity in acetonitrile at room temperature, and the imidazole compounds such as MNBCI and DNBCI can be obtained by reactions of 1.2-2.0 times CDI and nitrobenzyl alcohols with high nucleophilicity in THF at low temperature.

Decomposition temperatures of the synthesized imidazole derivatives were measured by TGA under nitrogen atmosphere. As summarized in Table I, 3-NBCI had the lowest decomposition temperature at $149^{\circ} \mathrm{C}$, while 2-NBCI showed the highest decomposition temperature at $182^{\circ} \mathrm{C}$. This is an important feature of the blocked imidazole derivatives for practical use as the catalyst for epoxy resins.

Absorption maxima $\left(\lambda_{\max }\right)$ of blocked imidazole compounds are important for photo-generation of free imidazole by UV- irradiation, and were measured in THF solution by UV spectra. As shown in Table I, $\lambda_{\max }$ of 2-NBCI, 3-NBCI, 4-NBCI, CNBCI, MNBCI, and DNBCI are 241, 252, 263, 243 and 303, 274, and $342 \mathrm{~nm}$, respectively. This means that the introduction of 4chloro, 5-methyl, or 4,5-dimethoxy group into 2-nitrobenzyloxy moiety red-shifted effectively the absorption of the blocked imidazole.

The solubility of the blocked imidazoles 2-NBCI, 3-NBCI, 4-NBCI, MNBCI, and DNBCI was examined. As summarized in Table II, although all blocked imidazoles were insoluble in $n$-hexane and diethyl ether at room temperature, MNBCI was soluble in the both solvents by heating and 4-NBCI was soluble in diethyl ether by heating. All blocked imidazoles were soluble in methanol, ethyl acetate, acetone, acetonitrile, chloroform, or THF. This means that these blocked imidazole compounds have ordinarily good solubility in common organic solvents.

\section{Photolysis of Blocked Imidazoles in THF Solution and in PMMA Film}

Photolysis of 2-NBCI was carried out in THF solution in a cylindrical quartz reactor under UV-irradiation using a 500-W high-pressure mercury lamp. As shown in Figure 1, 2-NBCI decomposed gradually under UV-irradiation. The reaction proceeded with $70 \%$ conversion, as determined by the intensity of proton signals at $5.8 \mathrm{ppm}$ due to methylene protons $v s$. at $7.1 \mathrm{ppm}$ due to methin proton of the imidazole ring, after $5 \mathrm{~h}$ irradiation under nitrogen atmosphere (Figure 1). After irradiation, the ${ }^{1} \mathrm{H}$ NMR spectrum showed signal of $\mathrm{CHO}$ proton at $\delta=9.8 \mathrm{ppm}$ due to (2-nitroso)benzaldehyde. This shows that photo-deprotection of 2-NBCI to produce free imidazole occurs in solution under UV-irradiation

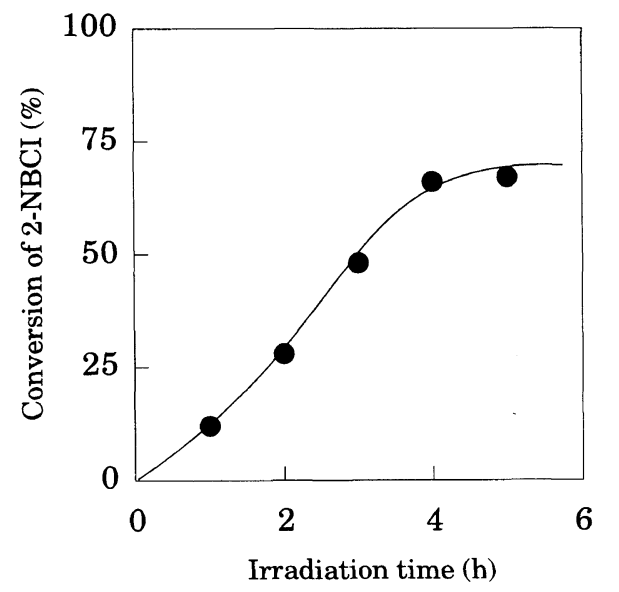

Figure 1. Time-conversion curve of photolysis of 2-NBCI in THF solution.

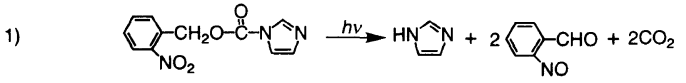

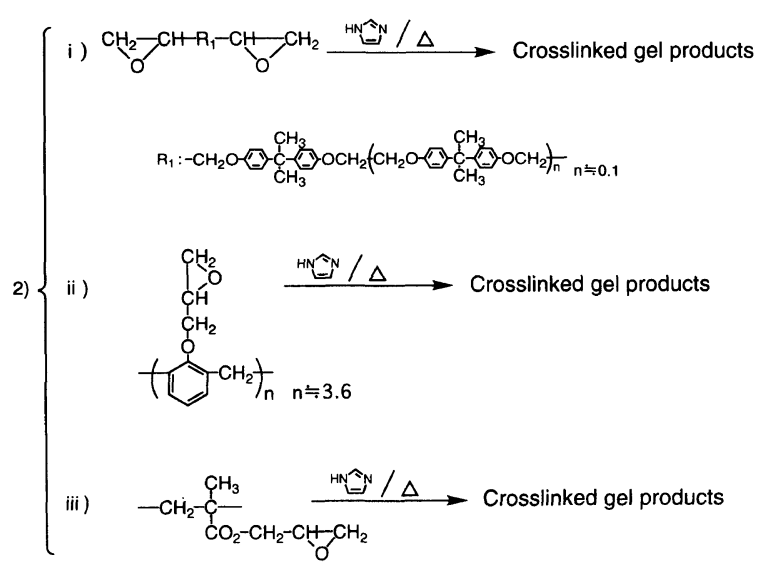

Scheme 2.

(Scheme 2).

The photolysis of 2-NBCI in PMMA film was examined on a $\mathrm{KBr}$ plate. The rate of disappearance of 2-NBCI was measured by monitoring the $\mathrm{NO}_{2}$ group at $1523 \mathrm{~cm}^{-1}$ in the IR spectroscopy. Almost $100 \% 2-\mathrm{NBCI}$ decomposed to produce free imidazole in PMMA film after UV-irradiation for $60 \mathrm{~min}$ (Figure 2). 3-NBCI and 4-NBCI also decomposed upon irradiation; however, the rates of photolysis of 3-NBCI and 4-NBCI were slower than that of 2-NBCI under the same conditions. This indicates that 2-nitrobenzyloxycarbonyl group is a better protecting group than 3-nitrobenzyloxycarbonyl or 4- 


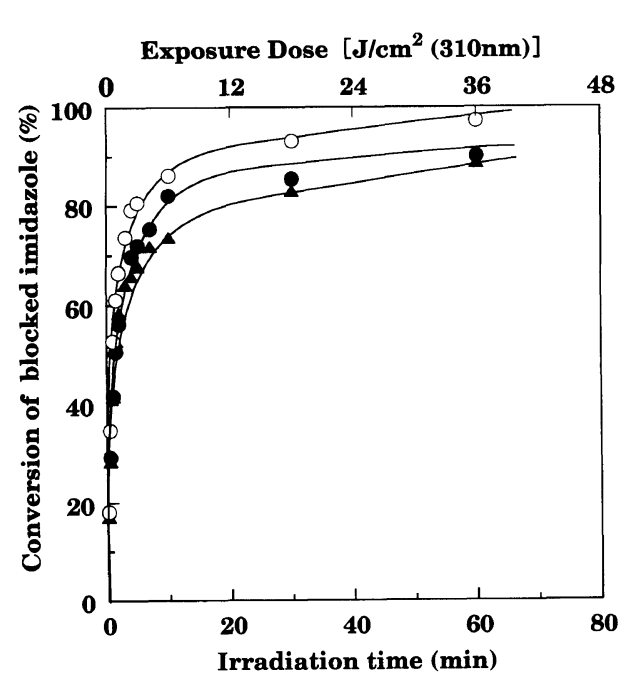

Figure 2. Time-conversion curve of photolysis of blocked imidazoles

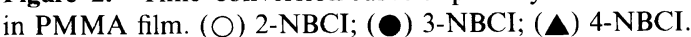

nitrobenzyloxycarbonyl groups for the photo-production of free imidazole. Similar results have been found ${ }^{17}$ on the photo-decomposition of poly(2-nitrobenzyl methacrylate), poly(3-nitrobenzyl methacrylate), and poly(4-nitrobenzyl methacrylate).

As shown in Figure 3, almost all DNBCI and MNBCI decomposed upon UV-irradiation for only $10 \mathrm{~min}$, although conversions of 2-NBCI and CNBCI were about 85 and $90 \%$, respectively, under the same irradiation conditions. This means that the introduction of a suitable chromophore such as 4,5-dimethoxy or 5-methyl group into the 2-nitrobenzyloxy moiety enhances strongly the rates of photo-decomposition of the blocked imidazole compounds due to the electronic effect of the substituent on the benzene ring. The introduction of chloro group into the 2-nitrobenzyloxy moiety increased the photodecomposition of the blocked imidazole compound, CNBCI. It seems that the red-shift of the UV absorptions of CNBCI, MNBCI, and DNBCI also may enhance each rate of photolysis.

\section{Photolysis of Blocked Imidazole in Epoxy Resin and Thermal Curing Reaction of Epoxy Resins Catalyzed by Photo-Generated Imidazole \\ The photolysis of 2-NBCI ( $10 \mathrm{~mol} \%$ to epoxide group)} in bisphenol-type epoxy resin (Epicoat 828 ) for $60 \mathrm{~min}$ $\left(39 \mathrm{~J} \mathrm{~cm}^{-2}\right)$ and $90 \mathrm{~min}\left(58 \mathrm{~J} \mathrm{~cm}^{-2}\right)$, respectively, followed by the thermal curing reaction of the epoxy resin at $120^{\circ} \mathrm{C}$ were performed on a $\mathrm{KBr}$ plate. The thermal curing reaction of the epoxy resin containing $10 \mathrm{~mol} \%$ of imidazole was examined under the same conditions as for the reference reaction. The rates of ring-opening of epoxide groups in the resin were measured from decrease in absorption peaks due to cyclic $\mathrm{C}-\mathrm{O}-\mathrm{C}$ stretching at $910 \mathrm{~cm}^{-1}$ using IR spectroscopy. As shown in Figure 4, the rate of conversion of epoxide group of the mixture of the resin with $10 \mathrm{~mol} \%$ of imidazole was faster than those of the photo-irradiated mixtures of the resin with $10 \mathrm{~mol} \%$ of $2-\mathrm{NBCI}$, and the conversion of epoxide group of the former mixture reached nearly $90 \%$ by heating at $120^{\circ} \mathrm{C}$ for $30 \mathrm{~min}$. The conversions of epoxide groups of the photo-irradiated mixtures for 60 and $90 \mathrm{~min}$ were 42 and $68 \%$, respectively, by heating

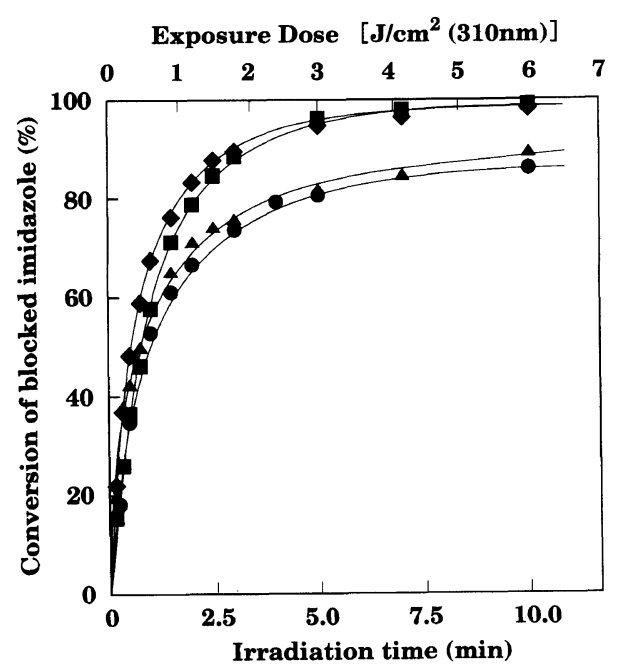

Figure 3. Rates of photolysis of blocked imidazoles in PMMA film.

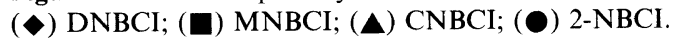

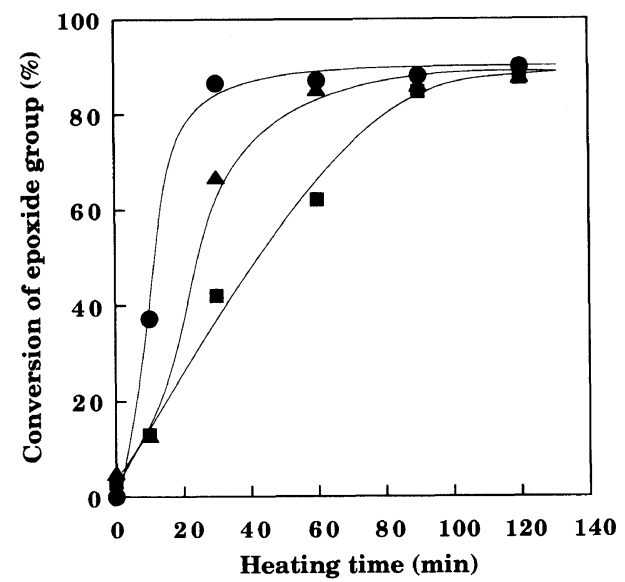

Figure 4. Rates of ring-opening of epoxy group in a mixture of bisphenol-type epoxy resin with 2 -NBCI ( $10 \mathrm{~mol} \%$ to epoxide group) or imidazole $\left(10 \mathrm{~mol} \%\right.$ to epoxide group) by heating at $120^{\circ} \mathrm{C}$. (O) with imidazole; (A) after UV-irradiation for $90 \mathrm{~min}$ with 2-NBCI; ( after UV-irradiation for $60 \mathrm{~min}$ with 2 -NBCI.

under the same conditions for $30 \mathrm{~min}$. These conversions reached nearly $90 \%$ by heating for $120 \mathrm{~min}$, and the cured mixtures became insoluble in THF and chloroform. This means that photo-generation of free imidazole in the epoxy resin mixture increases with irradiation time, and the photo-generated imidazole from 2-NBCI promotes effectively the thermal curing reaction of the epoxy resin (Scheme 2).

A mixture of the same epoxy resin with 2-NBCI ( $10 \mathrm{~mol} \%$ to the epoxide group) was irradiated with UV-light for $60 \mathrm{~min}$, and the mixture was heated at various temperatures. As shown in Figure 5, conversion of epoxide groups of the resin mixtures was about $5 \%$ after UV-irradiation for $60 \mathrm{~min}$ at room temperature, which was confirmed from decrease of absorption peak of cyclic ether at $910 \mathrm{~cm}^{-1}$ by the IR spectrum. This indicates that the ring-opening reaction of epoxide group in the resin may be partially catalyzed by photo-generated free imidazole during UV-irradiation. The conversion of epoxide group in the mixture increased with heating time and temperature, and reached 77,88 , and $98 \%$, respectively, after thermal treatment at 100,120 , and $140^{\circ} \mathrm{C}$ for $120 \mathrm{~min}$. Each cured mixture after heating for 


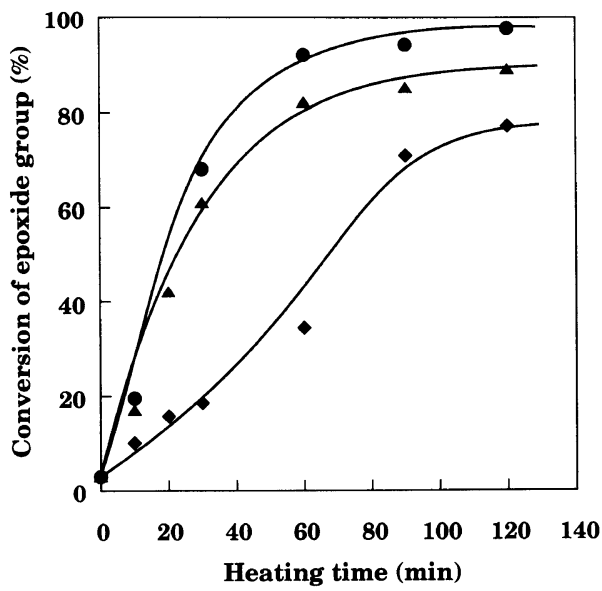

Figure 5. Rates of ring-opening of epoxy group in a mixture of bisphenol-type epoxy resin with 2-NBCI ( $10 \mathrm{~mol} \%$ to epoxy group) after UV-irradiation for $60 \mathrm{~min}$ followed by heating. $(\diamond)$ at $100^{\circ} \mathrm{C}$; (A) at $120^{\circ} \mathrm{C} ;(\mathbf{O})$ at $140^{\circ} \mathrm{C}$.

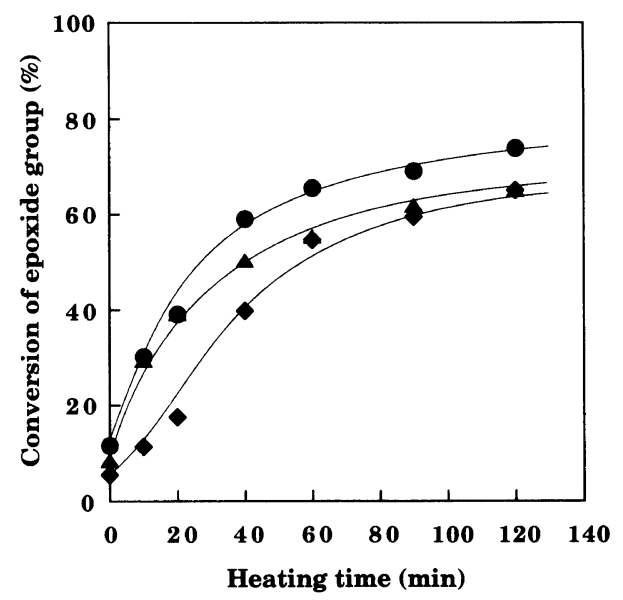

Figure 6. Rates of ring-opening of epoxy group in a mixture of novolac-type epoxy resin with 2 -NBCI $(10 \mathrm{~mol} \%$ to epoxy group) after UV-irradiation for $60 \mathrm{~min}$ followed by heating. $(\$)$ at $120^{\circ} \mathrm{C}$; $(\Delta)$ at $140^{\circ} \mathrm{C} ;(\mathbf{O})$ at $160^{\circ} \mathrm{C}$.

120 min became insoluble in THF and chloroform. This means that the thermal curing reaction of the epoxy resin catalyzed by photo-generated free imidazole is strongly affected by reaction temperature.

The photo-initiating thermal curing reaction of novolac-type epoxy resin (DEN 438) containing three or more epoxy groups in a molecule with 2 -NBCI $(10 \mathrm{~mol} \%$ to epoxide group) was also performed under the same conditions. As shown in Figure 6, conversion of epoxide groups of the resin mixtures was about 5-10\% after UV-irradiation for $60 \mathrm{~min}$ at room temperature. The conversion of epoxide group in the mixture increased with heating time and temperature, and reached 65,65 , and $73 \%$, respectively, after thermal treatment at 120 , 140 , and $160^{\circ} \mathrm{C}$ for $120 \mathrm{~min}$. Each cured mixture of the novolac-type epoxy resin with 2-NBCI was insoluble in THF and chloroform after UV-irradiation for $60 \mathrm{~min}$ followed by heating for $120 \mathrm{~min}$. These results indicate that thermal curing reaction of novolac-type epoxy resin with the photo-generated imidazole occurs as shown in Scheme 2, where $\mathrm{n}$ is the degree of polymerization, although the rate of ring opening of epoxide group of novolac-type epoxy resin was slower than that of epox-

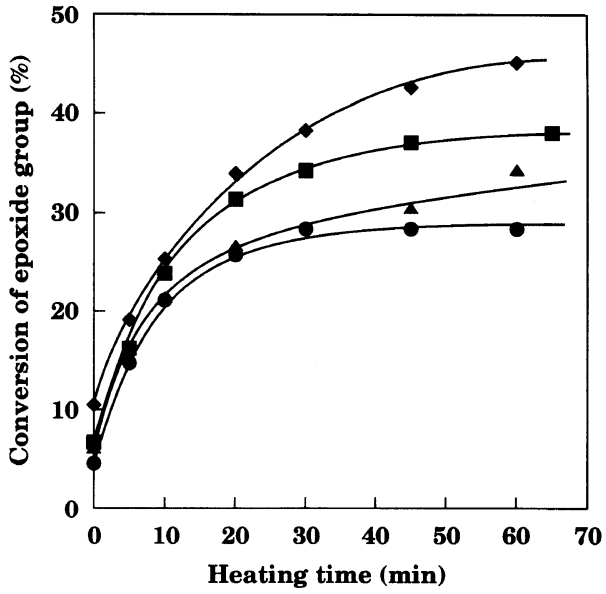

Figure 7. Rates of ring-opening of epoxy group in mixtures of $\mathrm{P}\left(\mathrm{GMA}_{55}-\mathrm{MMA}_{45}\right)$ and various amounts of 2-NBCI after UVirradiation for $10 \mathrm{~min}$ followed by heating at $120^{\circ} \mathrm{C}$. (O) with $1 \mathrm{~mol} \%$ of $2-\mathrm{NBCI}$; $(\boldsymbol{\Delta})$ with $3 \mathrm{~mol} \%$ of $2-\mathrm{NBCI}$; ( $\mathbf{\square}$ ) with $5 \mathrm{~mol} \%$ of $2-\mathrm{NBCI}$; (•) with $10 \mathrm{~mol} \%$ of $2-\mathrm{NBCI}$.

ide group of bisphenol-type epoxy resin due to their structures.

The photo-initiating thermal curing reaction of $\mathrm{P}\left(\mathrm{GMA}_{55}-\mathrm{MMA}_{45}\right)$ film containing $1,3,5$, and $10 \mathrm{~mol} \%$ of 2-NBCI was carried out on $\mathrm{KBr}$ plates. Since about $80 \mathrm{~mol} \%$ of 2 -NBCI decomposed by UV-irradiation for $10 \mathrm{~min}\left(6 \mathrm{~J} \mathrm{~cm}{ }^{-2}\right)$ in PMMA film as shown in Figure 3, the photo-irradiation toward this system was performed only for $10 \mathrm{~min}$, and the thermal curing reaction at $120^{\circ} \mathrm{C}$. As shown in Figure 7, conversion of pendant epoxide groups in $\mathrm{P}\left(\mathrm{GMA}_{55}-\mathrm{MMA}_{45}\right)$ films containing 1, 3, 5, and $10 \mathrm{~mol} \%$ of $2-\mathrm{NBCI}$ increased with time, reaching $28,33,38$, and $45 \%$, respectively, by heating for $60 \mathrm{~min}$. All polymer films composed of $\mathrm{P}\left(\mathrm{GMA}_{55}-\mathrm{MMA}_{45}\right)$ and 2-NBCI became insoluble in THF and chloroform after UV-irradiation for $10 \mathrm{~min}$ followed by heating at $120^{\circ} \mathrm{C}$ for $60 \mathrm{~min}$ (Scheme 2). This shows that the photoinitiating thermal curing reaction of $\mathrm{P}\left(\mathrm{GMA}_{55}-\mathrm{MMA}_{45}\right)$ film is possible by the addition of a small amount of blocked imidazole compound and short time UV-irradiation.

\section{REFERENCES}

1. For example: (a) H. Kakiuchi, Ed., "Epoxy Resins," Shokodo, Tokyo, 1985; (b) R. S. Bauer, Ed., "Epoxy Resin Chemistry," ACS Symposium Series 114, The American Chemical Society, Washington, D.C., 1976; (c) R. S. Bauer, Ed., "Epoxy Resin Chemistry II," ACS Symposium Series 221, The American Chemical Society, Washington, D.C., 1983.

2. (a) T. Nishikubo and K. Tanaka, J. Appl. Polym. Sci., 33, 2821 (1987); (b) T. Nishikubo and A. Kameyama, Prog. Polym. Sci., 18, 963 (1993).

3. (a) S. P. Pappas and L. W. Hill, J. Coat. Tech., 53(675), 43 (1981); (b) S. P. Pappas, High Solids Coat., 8(1), 43 (1983).

4. (a) T. Endo and A. Arita, Makromol. Chem., Rapid Commun., 6, 137 (1985); (b) A. Kikkawa, T. Takata, and T. Endo, Makromol. Chem., 192, 655 (1991); (c) F. Hamazu, S. Akashi, T. Koizumi, T. Takata, and T. Endo, J. Polym. Sci., Part A, Polym. Chem., 29, 1845 (1991).

5. (a) S.-B. Lee, T. Takata, and T. Endo, Chem. Lett., 1861 (1989); (b) S.-B. Lee, T. Takata, and T. Endo, Macromolecules, 23, 431 (1990).

6. K. Takuma, T. Takata, and T. Endo, Macromolecules, 26, 862 (1993). 
7. S.-B. Lee, Y. -S. Park, K.-W. Lee, and T. Endo, Chem. Lett., 287 (1995).

8. (a) J. V. Crivello and J. H. W. Lam, J. Polym. Sci. Polym. Lett Ed., 17, 759 (1979); (b) J. V. Crivello and J. H. W. Lam, J. Polym. Sci. Polym. Chem. Ed., 17, 2877 (1979).

9. (a) J. V. Crivello, T. P. Lockhart, and J. L. Lee, J. Polym. Sci. Polym. Chem. Ed., 21, 97 (1983); (b) J. V. Crivallo, Adv. Polym. Sci., 62, 1 (1984).

10. M. R. Winkle and K. A. Graziano, J. Photopolym. Sci. Technol., 3, 419 (1990).

11. C. Kutal and C. G. Willson, J. Electrochem. Soc., 134, 2280 (1987).

12. (a) K. Ito, M. Nishimura, M. Sashio, and M. Tsunooka, Chem. Lett., 1153 (1992). (b) K. Ito, M. Nishimura, M. Sashio, and M. Tsunooka, J. Polym. Sci., Part A, Polym. Chem., 32, 1793 (1994). (c) K. Ito, Y. Shigeru, Y. Kawata, K. Ito, and M. Tsunooka,
Can. J. Chem., 73, 1924 (1995).

13. (a) J. F. Cameron and J. M. J. Frechet, J. Org. Chem., 55, 5919 (1990); (b) J. F. Cameron and J. M. J. Frechet, J. Am. Chem. Soc., 113, 4303 (1991); (c) J. M. J. Frechet, Pure \& Appl. Chem., 64, 1239 (1992).

14. (a) T. Nishikubo, E. Takehara, and A. Kameyama, Polym. J., 25, 421 (1993); (b) T. Nishikubo, E. Takehara, and A. Kameyama, J. Polym. Sci., Part A, Polym. Chem., 31, 3013 (1993).

15. (a) T. Nishikubo, A. Kameyama, and K. Kashiwagi, Polym. J., 26, 864 (1994); (b) T. Nishikubo, A. Kameyama, K. Kashiwagi, and N. Oyama, Polym. J., 28, 795 (1996).

16. T. Nishikubo, T. Kawashima, and S. Watanabe, J. Polym. Sci., Part A, Polym. Chem., 31, 1659 (1993).

17. T. Nishikubo, T. Iizawa, A. Takahashi, and T. Shimokawa, J. Polym. Sci., Part A, Polym. Chem., 28, 105 (1990). 